\title{
Comparative genomic analysis of Mycobacterium tuberculosis clinical isolates
}

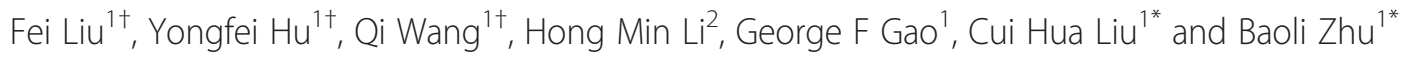

\begin{abstract}
Background: Due to excessive antibiotic use, drug-resistant Mycobacterium tuberculosis has become a serious public health threat and a major obstacle to disease control in many countries. To better understand the evolution of drug-resistant $M$. tuberculosis strains, we performed whole genome sequencing for $7 \mathrm{M}$. tuberculosis clinical isolates with different antibiotic resistance profiles and conducted comparative genomic analysis of gene variations among them.

Results: We observed that all 7 M. tuberculosis clinical isolates with different levels of drug resistance harbored similar numbers of SNPs, ranging from 1409-1464. The numbers of insertion/deletions (Indels) identified in the 7 isolates were also similar, ranging from 56 to 101. A total of 39 types of mutations were identified in drug resistance-associated loci, including 14 previously reported ones and 25 newly identified ones. Sixteen of the identified large Indels spanned PE-PPE-PGRS genes, which represents a major source of antigenic variability. Aside from SNPs and Indels, a CRISPR locus with varied spacers was observed in all 7 clinical isolates, suggesting that they might play an important role in plasticity of the M. tuberculosis genome. The nucleotide diversity ( $\Omega$ value) and selection intensity (dN/dS value) of the whole genome sequences of the 7 isolates were similar. The $\mathrm{dN} / \mathrm{dS}$ values were less than 1 for all 7 isolates (range from 0.608885 to 0.637365 ), supporting the notion that M. tuberculosis genomes undergo purifying selection. The $\int$ values and $\mathrm{dN} / \mathrm{dS}$ values were comparable between drug-susceptible and drug-resistant strains.

Conclusions: In this study, we show that clinical M. tuberculosis isolates exhibit distinct variations in terms of the distribution of SNP, Indels, CRISPR-cas locus, as well as the nucleotide diversity and selection intensity, but there are no generalizable differences between drug-susceptible and drug-resistant isolates on the genomic scale. Our study provides evidence strengthening the notion that the evolution of drug resistance among clinical M. tuberculosis isolates is clearly a complex and diversified process.
\end{abstract}

Keywords: Mycobacterium tuberculosis, Drug resistance, Single nucleotide polymorphisms, Whole genome sequencing, Evolution

\section{Background}

The emergence and transmission of drug-resistant $M$. tuberculosis strains, especially Multidrug-resistant (MDR) and extensively drug-resistant (XDR) strains pose significant clinical, economic, as well as societal challenges. According to WHO report, there were an estimated 8.6 million incident cases of TB worldwide in 2012. Most of the estimated number of cases in 2012 occurred in Asia (58\%) and the African Region (27\%). The five countries

\footnotetext{
*Correspondence: liucuihua@im.ac.cn; zhubaoli@im.ac.cn

${ }^{\dagger}$ Equal contributors

${ }^{1}$ CAS key Laboratory of Pathogenic Microbiology and Immunology, Institute of Microbiology, Chinese Academy of Sciences, Beijing, China

Full list of author information is available at the end of the article
}

with the largest number of incident cases include: India (2.0-2.4 million, in 2012), China (0.9-1.1 million, in 2012), South Africa (0.4-0.6 million, in 2012), Indonesia (0.4-0.5 million, in 2012) and Pakistan (0.3-0.5 million, in 2012). India and China alone accounted for $26 \%$ and $12 \%$ of global cases, respectively. In addition, the global estimate of the burden of MDR-TB was 300, 000 cases among notified TB patients in 2012. India and China were the two countries estimated to have the largest numbers of MDR-TB patients (both over 50,000) [1]. The latest nationwide baseline survey for TB drug resistance carried out in China for the 2007 and 2008 reported that $8.32 \%$ of pulmonary TB patients in China suffered from MDR$\mathrm{TB}$ and $0.68 \%$ from XDR-TB. In 2007, there were an

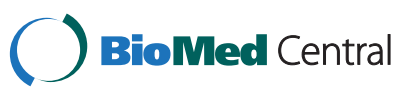


estimated 110,000 incident cases of MDR-TB and 8,200 incident cases of XDR-TB [2]. Furthermore, most cases of MDR- and XDR-TB were shown to be the result of primary transmission, suggesting that many of the new TB cases suffer from the most intractable types of highly drug-resistant $M$. tuberculosis strains [2,3]. Antibiotic susceptibility profiles and the corresponding resistance determinants of $M$. tuberculosis have been extensively reported. However, the genome variations and evolution of drug resistance in $M$. tuberculosis are still not well explained. Determining the genome components and variations within natural populations of $M$. tuberculosis isolates with different antibiotic susceptibility profiles may provide a novel perspective on the evolution of drug resistance in $M$. tuberculosis and enable us to better understand and control drug-resistant TB.

The Mycobacterium tuberculosis complex (MTBC) lineages were considered to be monomorphic, but more and more studies have confirmed the extensive genetic diversity and genome plasticity of the mycobacterial genome through molecular typing techniques such as IS6110-RFLP, spoligotyping, and MIRU-VNTR [4-6]. With the advent of high throughput Next Generation Sequencing technologies (NGS), multiple genome sequences from different strains of a single species can provide comprehensive information for exploring the relationship between genotypes and phenotypes with unprecedented resolution. In this study, we used the Illumina GAIIx sequencing platform to generate a highquality and annotated draft genome for $7 \mathrm{M}$. tuberculosis clinical isolates with different antibiotic resistance phenotypes in order to better understand the evolution of drug resistance in $M$. tuberculosis isolates in a clinical context. Comparative genomic analyses of these 7 strains as well as 7 other previously published $M$. tuberculosis genomes have revealed some genomic variations which might underlie diverse phenotypes among those strains, but no generalizable differences were identified between drug-susceptible and drug-resistant isolates on the genomic scale. Our study adds some new knowledge on genomic variability and evolution of drug-resistant $M$. tuberculosis.

\section{Results}

\section{Whole genome sequencing statistics}

The detailed epidemiologic and clinical data of the selected $M$. tuberculosis isolates were summarized in Table 1. The basic whole genome sequencing statistics are shown in Additional file 1: Table S1. The coverage ranged between $200 \times$ and $560 \times$, and the completion was 97.43-97.82\%. By comparing the sequenced $M$. tuberculosis clinical isolates to $\mathrm{H} 37 \mathrm{Rv}$, we observed that all 7 isolates with different levels and profiles of drug resistance harbored similar numbers of SNPs, ranging from 1409-1464. The numbers of insertion/deletions (Indels) identified in the 7 isolates were also similar, ranging from 56 to 101 .

\section{SNP clustering and distribution in the M. tuberculosis genomes}

Further comparative genomic analysis identified a total of 1871 non repetitive SNPs, among which a common pool of 1102 SNPs were shared by the 7 isolates. More detailed information on total SNPs as well as SNPs in each isolate relative to $\mathrm{H} 37 \mathrm{Rv}$ are summarized in Additional file 2: Table S2. To identify regions of SNP clustering, SNP density was estimated throughout the genomes using a sliding window of $5 \mathrm{~kb}$. The resulting

Table 1 Epidemiologic and clinical data of clinical M. tuberculosis isolates

\begin{tabular}{|c|c|c|c|c|c|c|c|c|c|}
\hline Isolates & Type & Drug resistance profiles ${ }^{a}$ & $\begin{array}{l}\text { Age, } \\
\text { years }\end{array}$ & Gender & $\begin{array}{l}\text { Geographic } \\
\text { location }\end{array}$ & $\begin{array}{l}\text { Year of } \\
\text { isolation }\end{array}$ & $\begin{array}{l}\text { Treatment } \\
\text { history }\end{array}$ & $\begin{array}{l}\text { Clinical } \\
\text { outcome }\end{array}$ & $\begin{array}{l}24 \text { locus MIRU- } \\
\text { VNTR profiles }\end{array}$ \\
\hline Mtb562 & Susceptible & None & 22 & Male & Liaoning & 2010 & New & Cure & $\begin{array}{l}223224163533- \\
454334682431\end{array}$ \\
\hline Mtb526 & MDR & INH, RMP, STR & 39 & Male & Shanxi & 2011 & Retreated & Cure & $\begin{array}{l}233224163533- \\
454344672432\end{array}$ \\
\hline Mtb194 & Pre-XDR & INH, RMP, STR, EMB, OFX, LVX & 21 & Female & Beijing & 2010 & New & Cure & $\begin{array}{l}213224163433- \\
243344572422\end{array}$ \\
\hline Mtb293 & Pre-XDR & INH, RMP, OFX, LVX, PAS, ETH & 35 & Female & Heilongjiang & 2009 & n.a. & n.a. & $\begin{array}{l}233324163523- \\
454344682432\end{array}$ \\
\hline Mtb940 & Pre-XDR & $\begin{array}{l}\text { INH, RMP, STR, EMB, PAS, OFX, LVX, } \\
\text { ETH }\end{array}$ & 63 & Male & Hebei & 2010 & New & Cure & $\begin{array}{l}233324143533- \\
254344672432\end{array}$ \\
\hline Mtb984 & XDR & INH, RMP, STR, EMB, OFX, LVX, KAN & 72 & Male & Anhui & 2011 & Retreated & Cure & $\begin{array}{l}233424173534- \\
254344482432\end{array}$ \\
\hline Mtb43 & XDR & $\begin{array}{l}\text { INH, RMP, STR, EMB, PZA, OFX, LVX, } \\
\text { KAN, CAP, AMK, PAS, ETH }\end{array}$ & 47 & Male & Henan & 2009 & Retreated & Died & $\begin{array}{l}232224153433- \\
454344582432\end{array}$ \\
\hline
\end{tabular}

n.a. $=$ not available.

INH, isoniazid; RMP, rifampicin; STR, streptomycin; EMB, ethambutol; PZA, pyrazinamide; OFX, ofloxacin; LVX, levofloxacin; KAN, kanamycin; CAP, capreomycin; AMK, amikacin; PAS, para-amino salicylic acid; ETH, ethionamide. 
SNP density map shows a non-random distribution of SNPs, with 25 regions having statistically significant clusters (red bars in Figure 1). The detailed information on the 25 regions with significantly high SNP density is shown in Additional file 2: Table S2. We further analyzed the distribution of SNPs according to the different classes of the Clusters of Orthologous Groups (COG) [7-9]. We found that SNPs were significantly under- represented in genes belonging to secondary metabolites biosynthesis, transport, and catabolism (class Q), while genes whose functions were unknown (class $S$ ) were significantly enriched in SNPs $(\mathrm{p}<0.01)$ (Additional file 3: Figure S1). SNPs were also slightly over-represented in genes belonging to several other classes such as class M (Cell wall/membrane/envelope biogenesis), class $\mathrm{R}$ (General function), class V (Defense mechanisms), class

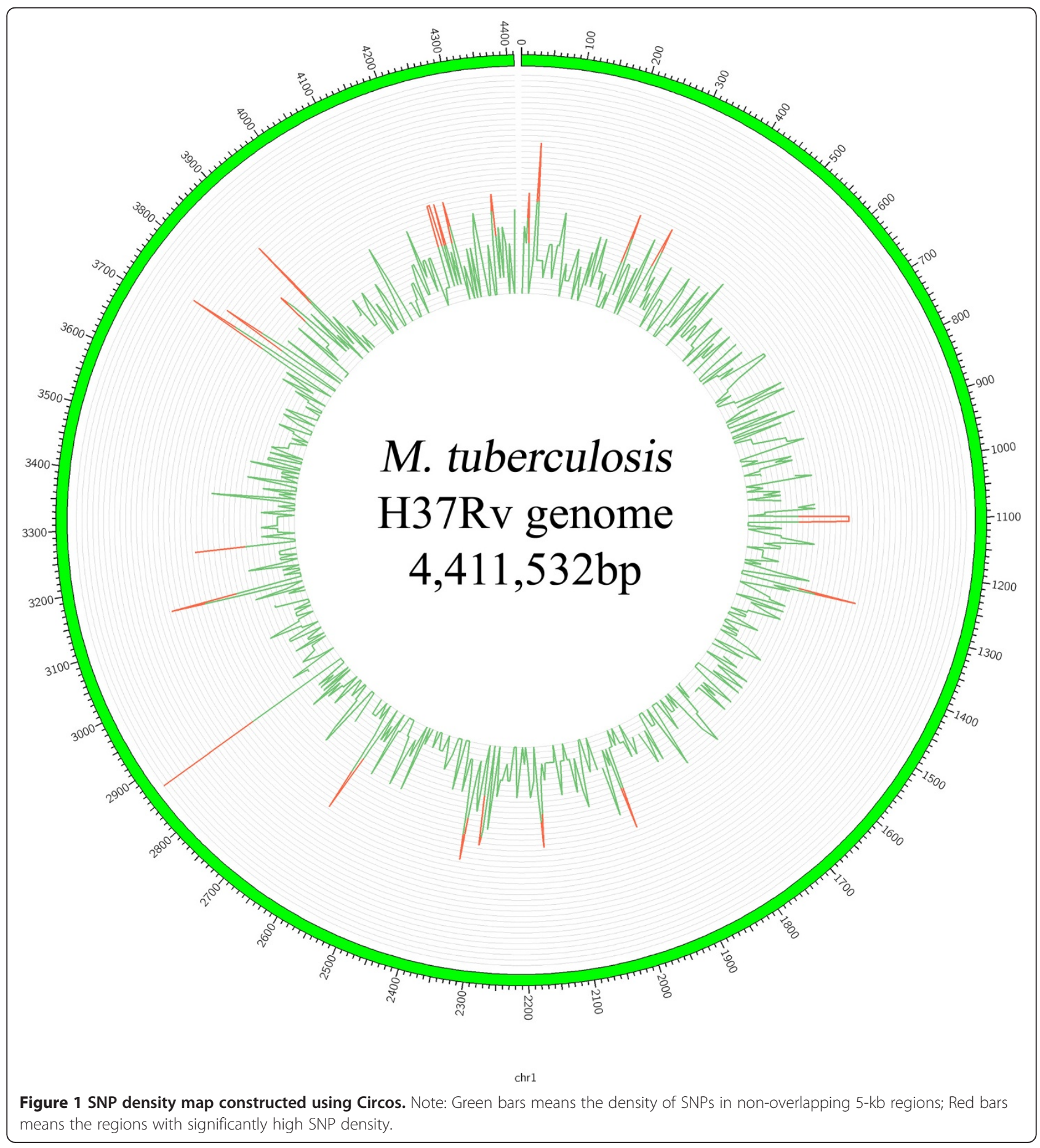


J (Translation, ribosomal structure and biogenesis), class K (Transcription), class $\mathrm{T}$ (Signal transduction mechanisms), and class $\mathrm{N}$ (Cell motility).

\section{Genomic insertions and deletions}

We further analyzed large insertions and deletions (designated as those insertions or deletions are of 20 base pair long or above) in clinical $M$. tuberculosis relative to M. tuberculosis H37Rv. In total, 1 non strain-specific and 29 strain-specific large insertions as well as 2 non strain-specific and 61 strain-specific large deletions were identified. Sixteen of those Indels spanned PE-PPEPGRS genes, which have been considered a major source of antigenic variability [10]. Many Indels were identified both in drug-susceptible and drug-resistant strains.

\section{CRISPR distribution in the $M$. tuberculosis genomes}

CRISPRfinder was used to identify putative CRISPR loci in the genomes of the $7 \mathrm{M}$. tuberculosis isolates. In contrast to the M. tuberculosis lab strain H37Rv, which was predicted to have two CRISPR loci, all the 7 clinical $M$. tuberculosis isolates sequenced in this study as well as two other previously sequenced clinical $M$. tuberculosis isolates (including CCDC5079 and CCDC5180) were predicted to have only one of the two CRISPR loci. While the spacers in the CRISPR were identical among 5 clinical isolates including CCDC5079, CCDC5180 and three of our clinical isolates (Mtb562, Mtb 526 and Mtb43), other isolates had high variability in the spacers (Additional file 4: Figure S2). No correlation between antibiotic resistance and the presence of CRISPR-cas locus was observed.

\section{Gene mutations associated with drug resistance in M. tuberculosis}

The detailed information on mutations identified in drug resistance-associated loci of the 7 Chinese clinical isolates is summarized in Table 2 and 3. A total of 39 types of mutations were identified in drug resistanceassociated loci, including 14 previously reported ones and 25 newly identified ones. The levels of correlation between phenotypic drug resistance and drug resistanceassociated mutations varied greatly for different drugs, ranging from $0 \%$ (for para-aminosalicylic acid and ethionamide) to $100 \%$ (isoniazid). We also identified 20 known or putative drug efflux pumps with nonsynonymous SNPs in MDR, pre-XDR and XDR $M$. tuberculosis isolates but not in $\mathrm{H} 37 \mathrm{Rv}$ strain (Additional file 5: Table S3). We further over expressed the mutated drug efflux pump genes in the drug-susceptible reference H37Rv strain and determined MICs of those recombinant strains. No increased drug resistance was observed for all examined strains over expressing mutated drug efflux pump genes. We also performed genetic studies by creating point mutations in the susceptible reference strain $\mathrm{H} 37 \mathrm{Rv}$ using the pJV53K system for some other potential drug resistance-associated mutations identified in this study [11], but also could not confirm their function in causing drug resistance (data not shown).

Table 2 SNPs and Indels identified in antibiotic resistance-associated regions in $M$. tuberculosis isolates

\begin{tabular}{|c|c|c|c|c|c|c|c|c|c|}
\hline \multirow[b]{2}{*}{ Isolates } & \multirow[b]{2}{*}{$\begin{array}{l}\text { Rv1483 } \\
(m a b A)^{b} \\
(\text { INH) }\end{array}$} & \multirow[b]{2}{*}{$\begin{array}{l}\text { Rv1484 } \\
\text { (inhA) } \\
\text { (INH) }\end{array}$} & \multicolumn{5}{|c|}{$\begin{array}{l}\text { Mutations in target gene or intergenic } \\
\text { regions (corresponding drugs) }\end{array}$} & \multirow[b]{2}{*}{$\begin{array}{l}\text { Rv0667 } \\
(r p o B)^{c}(\mathrm{RMP})\end{array}$} & \multirow[b]{2}{*}{$\begin{array}{l}\text { Rv0682 } \\
(r p s L)(S T R)\end{array}$} \\
\hline & & & $\begin{array}{l}\text { Rv1592c } \\
\text { (INH) }\end{array}$ & $\begin{array}{l}\text { Rv1908c } \\
\text { (katG) (INH) }\end{array}$ & $\begin{array}{l}\text { Rv2247 } \\
(\text { accD6) (INH) }\end{array}$ & $\begin{array}{l}\text { Rv2428 } \\
(\text { ahpC) (INH) }\end{array}$ & $\begin{array}{l}\text { Rv2846c } \\
(\operatorname{efp} A)(\mathrm{INH})\end{array}$ & & \\
\hline Mtb562 & None & None & T70(del),E32 ${ }^{\mathrm{e}, \mathrm{f}}, 1322 \mathrm{~V}^{\mathrm{f}, \mathrm{g}}$ & None & None & None & None & $\mathrm{A} 1075^{\mathrm{e}, \mathrm{f}}$ & None \\
\hline Mtb526 & None & None & T70(del),E32 ${ }^{\mathrm{e}, \mathrm{f}}, 1322 \mathrm{~V}^{\mathrm{f}, \mathrm{g}}$ & $\mathrm{S} 315 \mathrm{~T}^{\mathrm{d}, \mathrm{g}}, \mathrm{R} 463 \mathrm{~L}^{\mathrm{g}}$ & $\mathrm{D} 200^{\mathrm{e}, \mathrm{f}}, \mathrm{D} 229 \mathrm{G}^{\mathrm{g}}$ & $S 40 N^{f, g}$ & None & $\begin{array}{l}L 511 P^{d, g} \\
A 1075^{e, f^{\prime}}\end{array}$ & $\mathrm{K} 43 \mathrm{R}^{\mathrm{d}, \mathrm{g}}, \mathrm{K} 121^{\mathrm{e}, \mathrm{f}}$ \\
\hline Mtb194 & None & None & T70(del),E321 ${ }^{\mathrm{e}, \mathrm{f}}, 1322 \mathrm{~V}^{\mathrm{f}, \mathrm{g}}$ & $\mathrm{R} 463 \mathrm{~L}^{\mathrm{g}}$ & $\mathrm{D} 200^{\mathrm{e}, \mathrm{f}}, \mathrm{D} 229 \mathrm{G}^{\mathrm{g}}$ & None & None & $\mathrm{A} 1075^{\mathrm{e}, \mathrm{f}}$ & $\mathrm{K} 121^{\mathrm{eff}}$ \\
\hline Mtb293 & None & None & T70(del),E321 ${ }^{\mathrm{e}, \mathrm{f}}, 1322 \mathrm{~V}^{\mathrm{f}, \mathrm{g}}$ & $\mathrm{C} 171 \mathrm{G}^{\mathrm{f}, \mathrm{g}}, \mathrm{R} 463 \mathrm{~L}^{\mathrm{g}}$ & $\mathrm{D} 200^{\mathrm{e}, \mathrm{f}}, \mathrm{D} 229 \mathrm{G}^{\mathrm{g}}$ & None & None & $A 1075^{e, f}$ & $\mathrm{~K} 121^{\mathrm{e}}$ \\
\hline Mtb940 & None & None & 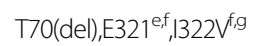 & $\mathrm{R} 463 \mathrm{~L}^{\mathrm{g}}$ & $D 200^{e, f}, D 229 G^{g}$ & None & None & $\mathrm{A} 1075^{\mathrm{e}, \mathrm{f}}$ & $\mathrm{K} 121^{\mathrm{e}, \mathrm{f}}$ \\
\hline Mtb984 & None & G3 e,f & T70(del),E321 ${ }^{\mathrm{ef}, \mathrm{,}} \mid 322 \mathrm{~V}^{\mathrm{f}, \mathrm{g}}$ & $\mathrm{S} 315 \mathrm{~T}^{\mathrm{d}, \mathrm{g}}, \mathrm{R} 463 \mathrm{~L}^{\mathrm{g}}$ & $\mathrm{D} 200^{\mathrm{e}, \mathrm{f}}, \mathrm{D} 229 \mathrm{G}^{\mathrm{g}}$ & None & $\mathrm{F} 128^{\mathrm{e}, \mathrm{f}}$ & $\begin{array}{l}\mathrm{L} 511 \mathrm{P}^{\mathrm{d}, \mathrm{g}}, \mathrm{S} 512 \mathrm{G}^{\mathrm{g}} \\
\mathrm{D} 516 \mathrm{G}^{\mathrm{g}}, \mathrm{A} 1075^{\mathrm{e}, f^{\prime}}\end{array}$ & $\mathrm{K} 43 \mathrm{R}^{\mathrm{d}, \mathrm{g}}, \mathrm{K} 121^{\mathrm{e}, \mathrm{f}}$ \\
\hline Mtb43 & $\mathrm{T}-8 \mathrm{C}^{\mathrm{d}}$ & $\mathrm{G} 3 \mathrm{e}^{\mathrm{e}, \mathrm{f}}$ & T70(del),E321 $1^{e, f}, 1322 V^{f, g}$ & $\mathrm{~S} 315 \mathrm{~T}^{\mathrm{d}, \mathrm{g}}, \mathrm{R} 463 \mathrm{~L}^{\mathrm{g}}$ & $\mathrm{D} 200^{\mathrm{e}, \mathrm{f}}, \mathrm{D} 229 \mathrm{G}^{\mathrm{g}}$ & None & None & S531L $L^{d, g}$ & $\mathrm{~K} 43 \mathrm{R}^{\mathrm{d}, \mathrm{g}}, \mathrm{K} 121^{\mathrm{e}, \mathrm{f}}$ \\
\hline \multicolumn{10}{|c|}{$\begin{array}{l}\text { a" } \mathrm{R} \text { ", resistance of isolates to the corresponding anti-TB drug; "S", sensitivity of isolates to the corresponding anti-TB drug; "del”, deletion; INH, isoniazid; RMP, } \\
\text { rifampicin; STR, streptomycin; EMB, ethambutol; PZA, pyrazinamide; OFX, ofloxacin; LVX, levofloxacin; KAN, kanamycin; CAP, capreomycin; AMK, amikacin; } \\
\text { ETH, ethionamide. } \\
\text { bintergenic regions. }\end{array}$} \\
\hline
\end{tabular}


Table 3 SNPs and identified in antibiotic resistance-associated regions in $M$. tuberculosis isolates

\begin{tabular}{|c|c|c|c|c|c|c|c|c|c|}
\hline \multirow[b]{2}{*}{ Isolates } & \multirow[b]{2}{*}{$\begin{array}{l}\text { Rv3919c (gidB) } \\
\text { (STR) }\end{array}$} & \multirow[b]{2}{*}{$\begin{array}{l}\text { Rv3793 (embC) } \\
\text { (EMB) }\end{array}$} & \multicolumn{5}{|c|}{ Mutations in target gene or intergenic regions (corresponding drugs) ${ }^{a}$} & \multirow[b]{2}{*}{$\begin{array}{l}\text { Rv1694 (tlyA) (KAN, } \\
\text { CAP, AMK) }\end{array}$} & \multirow[b]{2}{*}{$\begin{array}{l}\text { Rv3854c (ethA) } \\
\text { (ETH) }\end{array}$} \\
\hline & & & $\begin{array}{l}\text { Rv3794 (embA) } \\
\text { (EMB) }\end{array}$ & $\begin{array}{l}\text { Rv3795 (embB) } \\
\text { (EMB) }\end{array}$ & $\begin{array}{l}\text { Rv2043c (pncA) } \\
\text { (PZA) }\end{array}$ & $\begin{array}{l}\text { Rv0006 (gyrA) (OFX, } \\
\text { LVX) }\end{array}$ & $\begin{array}{l}\text { Rvnr01 (rrs) (KAN, } \\
\text { CAP, AMK) }\end{array}$ & & \\
\hline Mtb562 & $\mathrm{S}^{2} 00 \mathrm{~F}^{\mathrm{g}}$ & $\mathrm{R}^{2} 27^{\mathrm{e}}$ & None & None & None & S95 $\mathrm{T}^{\mathrm{g}}$ & None & None & $\mathrm{Q} 360 \mathrm{H}^{\mathrm{g}}$ \\
\hline Mtb526 & $\mathrm{E} 92 \mathrm{D}^{\mathrm{g}}, \mathrm{S} 100 \mathrm{~F}^{\mathrm{g}}, \mathrm{A} 205^{\mathrm{e}}$ & V $885 M^{f, g}, R 927^{e}$ & $\mathrm{C} 76^{\mathrm{e}}$ & None & None & $\mathrm{E} 21 \mathrm{Q}^{\mathrm{g}}, \mathrm{S} 95 \mathrm{~T}^{\mathrm{g}}, \mathrm{G} 668 \mathrm{D}^{\mathrm{f}, \mathrm{g}}$ & None & $\mathrm{L} 11^{\mathrm{e}}$ & $\mathrm{Q} 360 \mathrm{H}^{\mathrm{g}}$ \\
\hline Mtb194 & $\mathrm{E} 2 \mathrm{D}^{\mathrm{g}}, \mathrm{S} 100 \mathrm{~F}^{\mathrm{g}}, \mathrm{A} 205^{\mathrm{e}}$ & $\mathrm{V} 885 \mathrm{M}^{\mathrm{f}, \mathrm{g}}, \mathrm{R} 927^{\mathrm{e}}$ & $\mathrm{C} 76^{\mathrm{e}}$ & None & None & $\mathrm{E} 21 \mathrm{Q}^{\mathrm{g}}, \mathrm{S} 95 \mathrm{~T}^{\mathrm{g}}, \mathrm{G} 668 \mathrm{D}^{\mathrm{f}, \mathrm{g}}$ & None & $\mathrm{L} 11^{\mathrm{e}}$ & $\mathrm{Q} 360 \mathrm{H}^{\mathrm{g}}$ \\
\hline Mtb293 & $\mathrm{E} 92 \mathrm{D}^{\mathrm{g}}, \mathrm{S} 100 \mathrm{~F}^{\mathrm{g}}, \mathrm{A}^{2} 25^{\mathrm{e}}$ & V885 $M^{f, g}, R 927^{e}$ & $\mathrm{C} 76^{\mathrm{e}}$ & None & None & $\mathrm{E} 21 \mathrm{Q}^{\mathrm{g}}, \mathrm{S} 95 \mathrm{~T}^{\mathrm{g}}, \mathrm{G} 668 \mathrm{D}^{\mathrm{f}, \mathrm{g}}$ & None & $\mathrm{L} 11^{\mathrm{e}}$ & $\mathrm{Q} 360 \mathrm{H}^{\mathrm{g}}$ \\
\hline Mtb940 & $\mathrm{E} 92 \mathrm{D}^{\mathrm{g}}, \mathrm{S} 100 \mathrm{~F}^{\mathrm{g}}, \mathrm{A} 205^{\mathrm{e}}$ & $\mathrm{V} 885 \mathrm{M}^{\mathrm{f}, \mathrm{g}}, \mathrm{R} 927^{\mathrm{e}}$ & $\mathrm{C} 76^{\mathrm{e}}$ & None & None & $\mathrm{E} 21 \mathrm{Q}^{\mathrm{g}}, \mathrm{S} 95 \mathrm{~T}^{\mathrm{g}}, \mathrm{G} 668 \mathrm{D}^{\mathrm{f}, \mathrm{g}}$ & None & $\mathrm{L} 11^{\mathrm{e}}$ & $\mathrm{Q} 360 \mathrm{H}^{\mathrm{g}}$ \\
\hline Mtb984 & $\mathrm{E} 92 \mathrm{D}^{\mathrm{g}}, \mathrm{S} 100 \mathrm{~F}^{\mathrm{g}}, \mathrm{A}^{2} 25^{\mathrm{e}}$ & V885M $M^{f, g}, R 927^{e}$ & $\mathrm{G} 5 \mathrm{~S}^{\mathrm{f}, \mathrm{g}}, \mathrm{C} 76^{\mathrm{e}}$ & $\mathrm{G} 406 \mathrm{~S}^{\mathrm{d}, \mathrm{g}}$ & $\mathrm{F} 94 \mathrm{~S}^{\mathrm{f}, \mathrm{g}}$ & $\mathrm{E} 21 \mathrm{Q}^{\mathrm{g}}, \mathrm{D} 94 \mathrm{G}^{\mathrm{d}, \mathrm{g}}, \mathrm{S} 95 \mathrm{~T}^{\mathrm{g}}, \mathrm{G} 668 \mathrm{D}^{\mathrm{f}, \mathrm{g}}$ & None & $\mathrm{L} 11^{\mathrm{e}}$ & $\mathrm{Q} 360 \mathrm{H}^{\mathrm{g}}$ \\
\hline Mtb43 & $\mathrm{E}^{2} \mathrm{D}^{\mathrm{g}}, \mathrm{S} 100 \mathrm{~F}^{\mathrm{g}}, \mathrm{A} 205^{\mathrm{e}}$ & V885M $M^{f, g}$ & $\mathrm{C} 76^{\mathrm{e}}$ & M306V d,g & $\mathrm{T} 761^{9}$ & $\mathrm{E} 21 \mathrm{Q}^{g}, \mathrm{D} 94 \mathrm{G}^{\mathrm{d}, \mathrm{g}}, \mathrm{S} 95 \mathrm{~T}^{\mathrm{g}}, \mathrm{G} 668 \mathrm{D}^{\mathrm{f}, \mathrm{g}}$ & G1332A,A1401G & $\mathrm{L} 11^{\mathrm{e}}$ & $\mathrm{P} 164 \mathrm{~L}^{\mathrm{f}, \mathrm{g}}, \mathrm{Q} 360 \mathrm{H}^{\mathrm{g}}$ \\
\hline
\end{tabular}

“ "R", resistance of isolates to the corresponding anti-TB drug; " $\mathrm{S}$ ", sensitivity of isolates to the corresponding anti-TB drug; "del", deletion; INH, isoniazid; RMP,

rifampicin; STR, streptomycin; EMB, ethambutol; PZA, pyrazinamide; OFX, ofloxacin; LVX, levofloxacin; KAN, kanamycin; CAP, capreomycin; AMK, amikacin; ETH, ethionamide. bintergenic regions.

Cnucleotide mutational position is relative to Mycobacterium tuberculosis $\mathrm{H} 37 \mathrm{Rv} r p o B$, and amino acid position is relative to Escherichia coli numbering

ddrug resistance-asssociated mutations with high confidence.

esynonymous.

fnewly identified mutations.

${ }^{9}$ non-synonymous. 


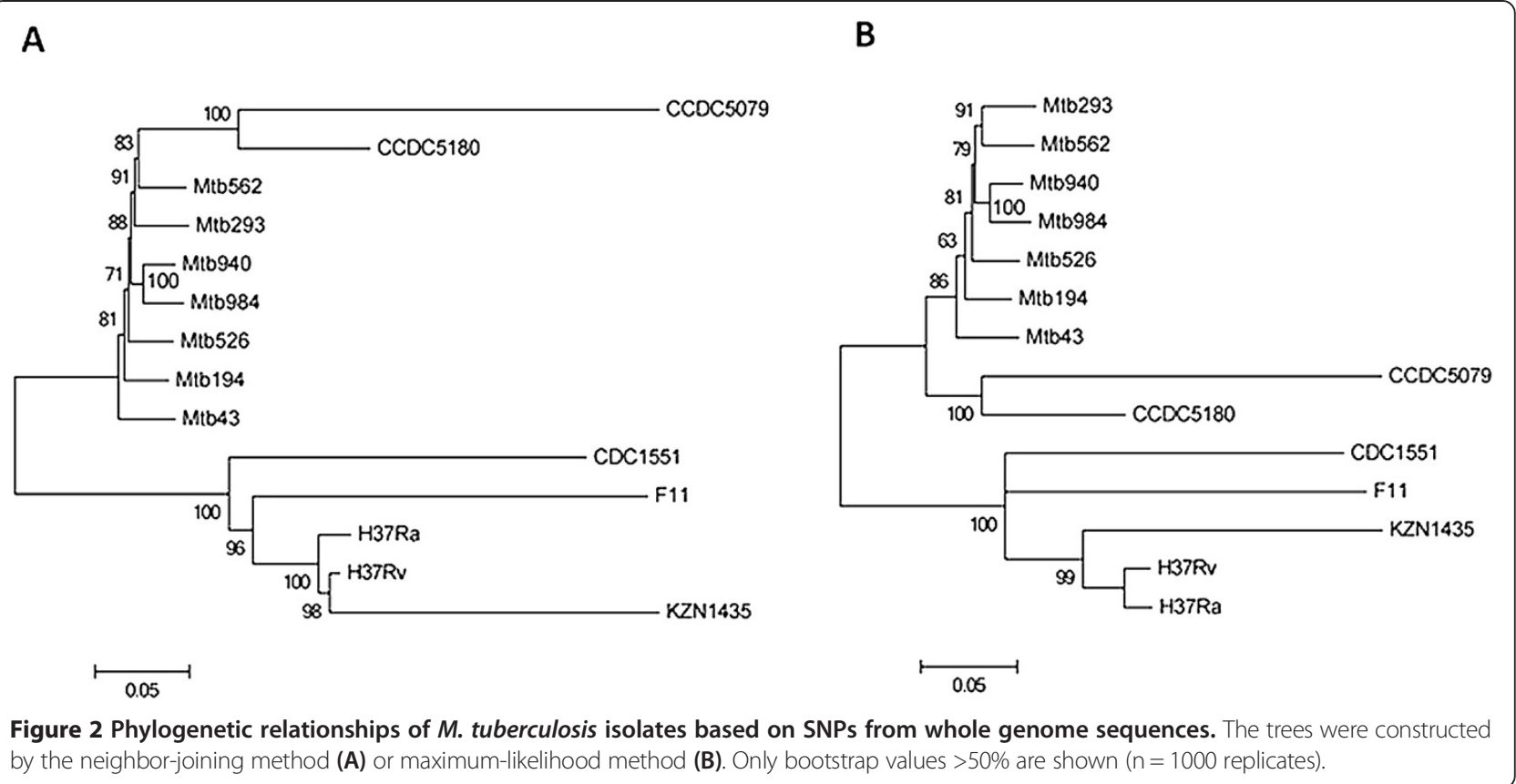

\section{Genetic diversity and selection intensity in the $M$. tuberculosis genomes}

We used the whole genome sequences of the $M$. tuberculosis isolates for genetic diversity and selection intensity analysis and the data were shown in Additional file 6: Table S4. The nucleotide diversity ( $\Lambda$ value) for the whole genome sequences of the 7 newly sequenced clinical isolates were similar, ranging from 0.00033 to 0.00036 . There was no significant differences in $\Lambda$ values between drug-susceptible isolates and drug-resistant isolates $(0.00024$ versus 0.00021$)$, while the $\Lambda$ value was significantly higher among clinical isolates $(0.00033)$ as compared with lab strains (0.00004). The $\mathrm{dN} / \mathrm{dS}$ values for the whole genome sequences were similar among isolates with different drug resistance profiles, ranging among 0.608885 to 0.637365 . There was no significant differences in $\mathrm{dN} / \mathrm{dS}$ values between drug-susceptible isolates and drug-resistant isolates (0.66891 versus 0.687259$)$, while the $\mathrm{dN} / \mathrm{dS}$ value was significantly lower among clinical isolates (0.66018) as compared with lab strains (0.765664). We observed significant differences in $\Lambda$ values between our 7 clinical isolates and 5 previously described clinical isolates $(0.00008$ versus 0.00057$)$. But when we analyzed our 7 isolates together with the two Beijing lineage strains (CCDC5079 and CCDC5080) from the 5 previously described clinical isolates, the $\Lambda$ value increased from 0.00008 to 0.00028 .

\section{Phylogenetic analysis of $M$. tuberculosis isolates}

Two phylogenetic trees including a neighbor-joining (NJ) tree and a maximum-likelihood (ML) tree were created based on SNPs from whole genome sequences of the 7 clinical M. tuberculosis isolates and other 7 completely sequenced $M$. tuberculosis strains. The phylogenetic relationships among different clinical isolates were similar in two phylogenetic trees (Figure 2). The 7 newly sequenced Chinese clinical isolates as well as the two previously sequenced Beijing lineage strains CCDC5079 and CCDC5180 formed a single clade.

\section{Discussion}

To determine the genome components and variations within natural populations of $M$. tuberculosis isolates and to better understand the evolution of drug resistance among those isolates, we explored the feasibility of using deep genome sequencing to characterize variations in clinical $M$. tuberculosis isolates with different drug susceptibility profiles. Our results suggest that the level of genetic diversity is independent of the drug resistance phenotype, since the isolates with different drug resistance profiles harbored similar numbers of SNPs, nucleotide diversity ( $\Lambda$ values), and selection intensity $(\mathrm{dN} / \mathrm{dS}$ values). The relatively high number of SNPs we identified in all isolates could be partially caused by natural variation, as we included all genes from 7 strains isolated from patients diversely located. Selective diversification of M. tuberculosis isolates might also explain an association between host response and strain genetic background as previously reported $[12,13]$. Several lines of evidence in this study support a significant role of natural selection in shaping M. tuberculosis genomes. First, the SNP distribution in genomes is not random, suggesting that diversifying selection is at work notably in certain genes such as those that play a role in cell wall/ 
membrane/envelope biogenesis (class $\mathrm{M}$ ) and in general function (class R), which tend to accumulate an excess of SNPs $[7,12,14,15]$. Second, in the SNP density map, many genes located in the regions with significantly high SNP density are involved in host-pathogen interactions and may contribute to strain-specific virulence attributes. For example, one region corresponds to a previously reported virulence operon including the genes Rv0986-Rv0988 that are present in one of horizontal genetic transfer (HGT) regions [7,16,17]. Another region with high density of SNPs was found in the ESX-1 locus (RD1 region), which includes a type VII secretion system [18]. But in the absence of the information about strainspecific differences in virulence, the high number of SNPs could also be the result of lateral gene transfer. Third, the dN/dS values were less than 1 for the genomes of all 7 isolates analyzed, consistent with genome-wide purifying selection. We have previously shown that the $\mathrm{dN} / \mathrm{dS}$ values for coding regions of drug resistanceassociated genes in MDR and XDR isolates were higher than 1, suggesting that exposure to drugs is among the major forces driving the high $\mathrm{dN} / \mathrm{dS}$ ratios in those drug resistance-associated genes [19]. But as suggested in this study, on the genome-wide scale, the clinical $M$. tuberculosis strains with different drug resistance profiles undergo similar levels of purifying selection. Consistently, results from a recent study suggest that the dominant effect of selection on natural $M$. tuberculosis population is removal of novel variants, with exceptions in certain group of genes such as those involved in defense [20].

Indels have a wide range of effects as a very important cause of phenotypic variability. The acquisition and loss of certain genes could provide pathogens with some advantages during infection and transmission. Thus, the Indel loci identified in this study are candidates for drug resistance or virulence-associated factors that may represent evolutionary signatures during the co-evolution of humans and pathogens. For example, the deletion of a polyketide synthase gene ( $p k s 5)$ with high homology to mycocerosic acid synthase is particularly intriguing because the product of this gene may be involved in the production of multimethylated branched lipids [21]. In addition, the pks5 mutant strain of $M$. tuberculosis H37Rv was shown to display severe growth defects in mice [22]. It is also worth noting that sixteen of those Indels spanned PE-PPE-PGRS genes, which have been considered a major source of antigenic variability [10]. In addition, two of those unique proteins code for putative membrane proteins (including MmpL1 and MmpL4) and may directly alter the interactions between pathogens and their hosts [23]. Since we identified many Indels including some of those above-mentioned virulence-associated genes within both drug-susceptible and drug-resistant strains, our results suggest that drug resistance in $M$. tuberculosis is not necessarily an indication of increased virulence. Our findings are consistent with the notion that the virulence of individual clinical M. tuberculosis isolate is dependent on multiple factors including strain genetic background and host immune responses [24].

A highly significant inverse correlation between the presence of CRISPR-cas locus and acquired antibiotic resistance was observed in E. faecalis, suggesting that antibiotic use inadvertently selects for enterococcal strains with compromised genome defense [25]. But in this study, no functional genes were identified in CRISPR locus and no correlation between antibiotic resistance and the presence of CRISPR-cas locus was observed in clinical M. tuberculosis isolates.

Using our previously established method of automatic TBDReaMDB-coupled analysis for drug resistance-associated mutations in $M$. tuberculosis isolates [19], we detected 25 types of unreported mutations, as well as 20 known or putative drug efflux pumps with non-sense SNPs in MDR, pre-XDR and XDR M. tuberculosis isolates, but we could not establish the association between over expression of those mutated drug efflux pumps with increased drug resistance in $M$. tuberculosis. It was reported previously that mutations or overexpression of Rv0194 and Rv2686c are associated with increased resistance to multiple drugs in $M$. tuberculosis [26,27]. But according to another recent study which aimed to compare the differences of the expression of 15 putative multidrug efflux pump genes in clinically isolated drug sensitive and MDR M. tuberculosis isolates, all the tested putative multidrug efflux pump genes in the drug-sensitive and MDR M. tuberculosis isolates have similar rates of expression [28]. Thus, the existence of mutations and over expression of the efflux pump genes might not be necessarily associated with increased drug resistance.

By closely examining the correlation of the phenotypic drug susceptibility profiles of the strains with mutations identified in their drug resistance-associated genes, we identified a few potential new genetic determinants of drug resistance. For example, while 5 (Mtb194, Mtb293, Mtb940, Mtb984, Mtb43) of the 7 strains exhibited phenotypic resistance to ofloxacin and levofloxacin, only 2 of them (Mtb984 and Mtb43) had gyrA D94G mutation known to confer resistance to fluoroquinolones. The other 3 had the same gyrA E21Q, G668D, and S95T mutations seen in fluoroquinolone susceptible strain Mtb526, indicating that these mutations are not the source of fluoroquinolone resistance. Similarly, among the 6 strains showing phenotypic resistance to rifampicin, 3 (Mtb194, Mtb293, Mtb940) only had the rpoB A1075 mutation, which was also present in the susceptible strain, suggesting the presence of other unknown mechanisms for rifampicin resistance in them. 
Since we identified no mutations by further examining other drug resistance-associated genes such as $\operatorname{gyr} B$, $\operatorname{gidB}$ and eis in those strains [29], we then performed genetic studies for those newly identified potential drug resistance-associated mutations, but failed to confirm their function in causing drug resistance either (data not shown). Thus, our observations demonstrated that though certain drug resistance-associated mutations such as rpoB S531L, katG S315T, gyrA D94G, embB M306V, rpsL K43R, and rrs A1401G could serve as useful markers for rapid detection of resistance in the clinical $M$. tuberculosis isolates, the accuracy and sensitivity of genetic-based drug resistance assays still need to be increased by further elucidation of unknown mechanisms of drug resistance, especially for second-line drugs [29-31]. It should also be pointed out that confirming drug resistance-associated mutations by genetic study could only examine the function of individual gene mutation without taking into consideration the whole genetic background of the strain, while based on the whole genome sequencing studies by us and a few others, there might be no common causes of drug resistance to multiple drugs. Rather, the MDR and XDR phenotypes could result from a combination of mutations in the genomes $[15,32,33]$.

The phylogenetic relationships among different clinical isolates were similar in two phylogenetic trees based on whole genome SNPs. The whole genome sequencing has been proposed as a sort of "gold standard" for strain typing in $M$. tuberculosis since it clarifies previous strain typing approaches used for phylogenetic and epidemiologic studies and provides more detailed genomic variation information. The observation that MDR, pre-XDR, and XDR isolates were located sporadically on different branches in phylogenetic trees based on SNPs from whole genome sequences of the $14 \mathrm{M}$. tuberculosis isolates further confirms our previous observation that they have evolved and acquired mutations independently on multiple occasions. The observation that isolates from China were phylogenetically distant from the isolates from other regions such as the KZN strain from South Africa in the phylogenetic trees also confirmed our previous observation that drug-resistant M. tuberculosis strains from different geographic regions have distinct evolutionary pathways [19]. The close phylogenetic relatedness among the 7 clinical $M$. tuberculosis isolates could also be best supported by the analysis of specific SNPs in drug resistance-associated genes. The presence of identical uncommon mutations in many of those genes among the 7 strains (e.g. I322V in Rv1592c, R463L in katG, A1075 in rpoB, G668D in gyrA etc.) is indicative of a single cluster of strains circulating in the population. The finding of high levels of clustering and minimal strain diversity among MDR/XDR $M$. tuberculosis strains within a population has been described previously [34].

This study has several limitations. Firstly, since the 7 clinical $M$. tuberculosis isolates included in the analysis all belonged to the Beijing lineage, thus it is possible that similarities and differences between different strain groups may be explained by phylogenetic lineages, rather than phenotypic differences. By comparing our 7 clinical isolates with 5 previously described clinical isolates from diverse lineages and countries of origin, we did observe significantly higher $\Lambda$ value for those 5 previously described clinical isolates. However, when we analyzed our 7 Beijing lineage isolates together with two previously described Beijing lineage isolates (CCDC5180: resistant to four first-line drugs; CCDC5079: susceptible strain), the $\Lambda$ value increased significantly, we thus suggest that genomic variations we observed among different groups of isolates are unlikely caused completely by phylogenetic lineages, but rather associated with diverse phenotypes of the isolates. Secondly, this study was limited by the relatively small number of isolates included in the analysis. It is likely that a larger sample with diverse lineages and countries of origin would probably reveal more information on genomic variations and evolution of drug-resistant $M$. tuberculosis strains.

\section{Conclusions}

In this study, by performing whole genome sequencing study, we show that though clinical M. tuberculosis isolates have a certain degree of similarity in their genetic make-up, they exhibit distinct variations in terms of the distribution of SNP, Indels, CRISPR-cas locus, as well as the nucleotide diversity and selection intensity. No generalizable differences were identified between drugsusceptible and drug-resistant isolates on the genomic scale. Our study provides evidence strengthening the notion that the evolution of drug resistance among clinical M. tuberculosis isolates is clearly a complex and diversified process. Several questions remain further in-depth investigations, such as whether drug susceptibility is affected by the deletion of specific genes and disabling of specific metabolic pathways. In addition, further studies using a larger sampling of $M$. tuberculosis isolates from diverse lineages are warranted to better understand the evolution of drug-resistant M. tuberculosis strains.

\section{Methods}

Selection of strains for genome sequencing and comparative genomic analysis

Seven M. tuberculosis clinical strains used for whole genome sequencing in this study were obtained from a TB referral hospital in Beijing, China during the period 2009-2011 [3]. The epidemiologic and clinical data of the patients were extracted from the subjects' medical 
records. The selected $M$. tuberculosis clinical isolates had different antibiotic susceptibility profiles (including 1 susceptible isolate, $1 \mathrm{MDR}$ isolate, 3 pre-XDR isolates and $2 \mathrm{XDR}$ isolate). The median age of the 7 patients were 39.02 (range: 21-72) years. All 7 patients were HIV-negative adults. All 7 isolates have the Beijing spoligotype (000000000003771) based on the virtual spoligotyping analysis results. For comparative analysis, genome sequences of two lab strains including $\mathrm{H} 37 \mathrm{Rv}$ (NC_000962) and H37Ra (NC_009525) as well as other five previously sequenced clinical isolates including KZN_1435 (NC_012943), F11 (NC_009565), CDC1551 (NC_002755), CCDC5079 (NC_017523), and CCDC51 80 (NC_017522) were downloaded from the NCBI website (fttp://ftp.ncbi.nih.gov/genomes/Bacteria/). This study was approved by the Ethics Committee of the 309 Hospital and the Institute of Microbiology, Chinese Academy of Sciences, Beijing, China.

\section{Cultures and drug susceptibility testing}

Cultures and drug susceptibility testing (DST) were conducted as described previously [19]. Briefly, sputum specimens were collected, treated and cultured according to the manufacturer's instructions using the BACTEC MGIT 960 system (Becton Dickinson Diagnostic Systems, Sparks, MD, USA). Cultures positive for growth were examined by microscopy for the presence of acidfast bacilli after Ziehl-Neelsen staining. Identification of M. tuberculosis was performed using p-nitrobenzoic acid and thiophene carboxylic acid hydrazine resistance tests as well as PCR tests. M. tuberculosis isolates were further confirmed by $16 \mathrm{~S}$ rDNA sequencing. DST was conducted using the indirect proportion method on Middlebrook $7 \mathrm{H} 10$ agar containing $10 \%$ oleic acidalbumin-dextrose-catalase (Difco) and $0.5 \%$ glycerol according to the WHO guidelines. The concentrations of the drugs used were as follows: isoniazid $(0.2 \mathrm{ug} / \mathrm{mL})$, rifampicin (1 ug/mL), ethambutol $(5 \mathrm{ug} / \mathrm{mL})$, streptomycin $(2 \mathrm{ug} / \mathrm{mL})$, pyrazinamide $(100 \mathrm{ug} / \mathrm{mL})$, ofloxacin (2 ug/mL), levofloxacin (2 ug/mL), kanamycin (5 ug/mL), capreomycin (10 ug/mL), amikacin (1 ug/mL), ethionamide $(5 \mathrm{ug} / \mathrm{mL})$, para-aminosalicylic acid $(2 \mathrm{ug} / \mathrm{mL})$. Quality control was performed during susceptibility testing using the reference strains provided by the National institute for the control of pharmaceutical and biological products (China). All drugs were obtained from Sigma Life Science Company (USA).

\section{Genotyping of $M$. tuberculosis isolates}

In silico MIRU-VNTR genotyping of the M. tuberculosis isolates was conducted. To predict the number of repeats at each locus of MIRUs, 24 VNTR sequences from $\mathrm{H} 37 \mathrm{Rv}$ genome were aligned to each assembled genome. The Tandem Repeat Finder algorithm was also used to predict the MIRU-VNTR type of each strain [35]. The in silico MIRU-VNTR results were confirmed by performing experiments following the 24 locus MIRU-VNTR genotyping protocol described by Supply et al. [6]. Virtual spoligotyping was performed by aligning (without gaps) all the reads obtained for each strain against each of the 43 spacer sequences (26-bp oligos) from the direct repeats (DR) regions. The number of matching reads for each spacer was counted, considering both forward and reverse-complemented sequences, and accepting up to 1 nucleotide mismatch. Spacers with 0 matches were interpreted as missing. In addition, we also used SpolPred [36], a well-established genotyping technique based on the presence of unique DNA sequences in $M$. tuberculosis, to predict the spoligotype of each strain.

\section{DNA preparation and whole genome sequencing}

A single colony from $7 \mathrm{H} 10$ plate was transferred into 7H9 liquid medium supplemented with OADC and Tween-80, cultured to 0.5 at $\mathrm{OD}_{600}$, harvested by centrifugation and resuspended in TE pH8.0 [0.01 M Tris$\mathrm{HCl}, 0.001 \mathrm{M}$ EDTA (pH 8.0)]. Genomic DNA was extracted with phenol/chloroform/isoamyl alcohol (25: 24: 1, v/v), precipitated with isopropanol, washed with $75 \%$ ethanol and finally resuspended in TE pH8.0. Genome sequencing was performed by BerryGenomics (Beijing, China). We used a whole genome shotgun sequencing strategy and Illumina Genome Analyser sequencing technology. A $100 \mathrm{bp}$ paired-end run was performed with the seven $M$. tuberculosis strains in two lanes. Genomic DNA was sheared by a nebulizer to generate DNA fragments for the Illumina Paried-End Sequencing method. DNA libraries (15-30 ng/ $\mathrm{ll}$ ) were constructed by ligating the specific oligonucleotides (Illumina adapters) designed for PE sequencing to both ends of DNA fragments with the TA cloning method. The ligated DNA was then size selected on a $2 \%$ agarose gel. DNA fragments of about $500 \mathrm{bp}$ were excised from the gel. DNA was then recovered using a Qiagen gel extraction kit and was PCR amplified to produce the final DNA library. Five picomoles of DNA from each strain were loaded onto two lanes of the sequencing chip, and the clusters were generated on the cluster generation station of the GAIIx using the Illumina cluster generation kit. Bacteriophage $\times 174$ DNA was used as a control. In the case of paired-end reads, distinct adaptors from Illumina were ligated to each end with PCR primers that allowed reading of each end as separate runs. The sequencing reaction was run for 100 cycles (tagging, imaging, and cleavage of one terminal base at a time), and four images of each tile on the chip were taken in different wavelengths for exciting each basespecific fluorophore. For paired-end reads, data were collected as two sets of matched 100-bp reads. Reads for 
each of the indexed samples were then separated using a custom Perl script (Additional file 7: Script 1). Image analysis and base calling were done using the Illumina GA Pipeline software.

\section{Genome assembly and annotation}

Short reads were assembled using SOAPdenovo (http:// soap.genomics.org.cn), a genome assembler developed specifically for next-generation short-read sequences. As the algorithm is sensitive to sequencing errors, lowquality reads were filtered, and high-quality reads were used for de novo assembly. Sequences were filtered for low quality reads using the DynamicTrim and LengthSort Perl scripts within SolexaQA. These scripts trimmed each read to the longest contiguous read segment for which the quality score at each base was greater than $\mathrm{p}=0.05$ (approximately equivalent to a Phred score of 13), and then removed sequence reads shorter than 25 bp respectively. Where one sequence of a pair was removed, the remaining sequence was put into a separate file and used as a singleton during de novo assembly. The SOAP GapCloser was also used to close gaps where possible after assembly.

The protein-coding genes were predicted using Glimmer 3.02 [37], while tRNAscan-SE [38] and RNAmmer [39] were used to identify tRNA and rRNA, respectively. The genome sequence was also uploaded into Rapid Annotation using Subsystem Technology (RAST) [40] to check the annotated sequences. The functions of predicted protein-coding genes were then annotated through comparisons with the databases of NCBI-NR, COG, and KEGG.

\section{Nucleotide sequence accession numbers}

Whole genome sequencing projects for 7 clinical $M$. tuberculosis isolates Mtb562, Mtb194, Mtb293, Mtb526, Mtb940, Mtb984, and Mtb43 have been deposited in GenBank under accession numbers AUTG00000000, AUNH00000000, AUPX00000000, AUTF00000000, AU TX00000000, AUTY00000000, and AUPO00000000, respectively.

\section{SNP detection and analysis}

For the sequenced genomes, SOAPsnp (http://soap.genomics.org.cn/soapsnp.html) was used to score SNPs from aligned reads [41]. The short reads were aligned onto the H37Rv genome reference using the SOAP2 program [18]. To obtain reliable alignment hits, at most two mismatches were allowed between the read and the reference. The alignments with the least number of differences were defined as "best hits." If there was only one single best hit for a read, then the read was taken as uniquely placed; a read with multiple equal best hits was taken as repeatedly placed. For paired-end reads, two reads belonging to a pair were aligned together with both in the correct orientation and with a proper span size on the reference. The 100 -bp reads that were generated for each strain were mapped against H37Rv as a reference sequence via ungapped alignments allowing up to two mismatches. For reads that mapped to multiple locations, one was chosen at random. For paired-end data, mapping locations of each read were restricted to sites within $300 \mathrm{bp}$ of mapping locations of its partner. SOAPsnp results were filtered as follows: 1) The read coverage of the SNP site was more than five; 2) The Illumina quality score of either allele was more than $30 ; 3$ ) The count of all mapped best base is more than two times the count of all mapped second best base. In addition, BWA 0.6.2 [42] and SAMtools 0.1.18 [43] were used to confirm our results. The Illumina reads were first aligned by BWA with default parameters for each sample. The aligned results were piped to SAMtools for conversion of BWA output format to BAM format and to perform SNP analysis. For the other genomes, all specific SNPs for each strain were manually inspected by taking into account if SNPs were detected by the two aligners including MAUVE [44] and MUMmer 3.2 [45]. From all SNPs identified in the sequenced genome sequences, the density of SNPs was calculated throughout the $M$. tuberculosis $\mathrm{H} 37 \mathrm{Rv}$ genome using a slidingwindow size of $5 \mathrm{~kb}$ (step of the sliding window $=5 \mathrm{~kb}$ ). This analysis led to the construction of a SNP clustering map using Circos [46].

\section{Insertion and deletion (Indel) analysis}

Three different methods were used to detect Indels: 1) Multiple alignment of genomic sequences was performed by using Mauve multiple alignment software and the progressive alignment option. The output file produced by Mauve was parsed by using a custom Perl script to retrieve multiple aligned sequences for Indel loci (Additional file 8: Script 2); 2) For each genomewide Ilumina sequence dataset, the sequence reads were aligned against the reference genome sequence using BWA 0.6.2 [42]. Then SAMTOOLS 0.1.18 [43], which is based on a Bayesian model for Indel calling, was used to perform the analysis using the default Indel detection parameters, with a small increase in the coverage threshold (-D 200); 3) Indel from paired-end mapping data were identified and visualized with inGAP-SV [47], which uses read depth and read pair data to detect and visualize large and complex sequence variation.

\section{CRISPR locus identification}

For published genome sequences, CRISPR loci were retrieved from the CRISPRdb database [48]. Alternatively, the detection of CRISPR loci in our 7 draft genome 
sequences was achieved using CRISPRFinder [48]. BLAST was used for similarity searches between CRISPR spacer sequences and existing sequences in the GenBank database limited to Bacteria (taxid: 2) or Viruses (taxid: 10239) entries. Only matches showing $100 \%$ identity over the complete CRISPR spacer sequences were retained, and matches to sequences found within CRISPR loci were ignored.

\section{Identification of gene mutations associated with drug resistance}

Mutations in M. tuberculosis antibiotic resistance-associated genes and inter-genic regions were downloaded from the TB Drug Resistance Mutation Database (TBDReaMDB) [49], a comprehensive database providing all reported mutations associated with TB drug resistance through a publicly accessible web site: http://www.tbdreamdb.com, to provide information for comparison analysis of drug resistanceassociated mutation profiles for the 7 sequenced $M$. tuberculosis isolates. To confirm the association between specific gene mutations and drug resistance, we amplified the putative drug resistance-associated genes with mutations from the genomic DNA of clinical $M$. tuberculosis isolates by PCR, and cloned them into the plasmid pMV261, a mycobacterial replicating vector, then electroporated the recombinant vectors into the drug-susceptible reference $\mathrm{H} 37 \mathrm{Rv}$ strain for drug susceptibility testing. All the experiments were repeated at least 3 times.

\section{Genetic diversity and selection intensity analysis}

The program DnaSP software version 5.10 was used to investigate the genetic diversity of the whole genome sequences of the M. tuberculosis isolates [50]. The genetic diversity were measured by haplotype $(\mathrm{H})$, diversity of haplotype (Hd), nucleotide diversity (p), and the average number of nucleotide differences (K). The sequences of the coding regions from each isolate were concatenated and the resulting sequences were used to determine the number of non-synonymous $(\mathrm{dN})$ and synonymous $(\mathrm{dS})$ substitutions per site. To test the selection intensity, the ratios of $\mathrm{dN} / \mathrm{dS}$ were calculated for each pairwise comparison, and two-sided Z-test was used to determine the level of significance.

\section{Phylogenetic analysis}

The neighbor-joining (NJ) and maximum-likelihood (ML) phylogenetic trees were constructed in MEGA5 [51] based on SNPs from whole genome sequences. The reliability of each node was estimated from 1000 random bootstrap resamplings of the data. The phylogenetic data have been deposited in TreeBase under the accession number 15638 (http://purl.org/phylo/treebase/phylows/study/TB2:S15638).

\section{Additional files}

\begin{abstract}
Additional file 1: Table S1. Sequencing statistics of M. tuberculosis isolates. Additional file 2: Table S2. Regions with significantly high SNP density. Additional file 3: Figure S1. Distribution of SNPS according to the Clusters of Orthologous Groups (COG) classification. (U) Intracellular trafficking and secretion; ( $)$ Defense mechanisms; (D) Cell cycle control, mitosis, and meiosis; (F) Nucleotide transport and metabolism; (O) Post-translational modification, protein turnover, chaperones; [O] Posttranslational modification, protein turnover, chaperones; [J] Translation, ribosomal structure and biogenesis; $(\mathrm{H})$ Coenzyme transport and metabolism; [M] Cell wall/membrane/envelope biogenesis; [S] Function unknown; [K] Transcription; (P) Inorganic ion transport and metabolism; (T) Signal transduction mechanisms; (G) Carbohydrate transport and metabolism; (N) Cell motility; (C) Energy production and conversion; $(\mathrm{L})$ Replication, recombination, and repair; $[\mathrm{E}]$ Amino acid transport and metabolism; (I) Lipid transport and metabolism; (R) General function; (Q) Secondary metabolites biosynthesis, transport, and catabolism. $\left(^{*}\right)$ Class with significant over-representation and less-representation of SNPS $(p<0.01)$.
\end{abstract}

Additional file 4: Figure S2. Overview of the CRISPR loci in M. tuberculosis strains. Spacers are shown as diamonds and repeats as rectangles. In each CRISPR, spacers with identical sequence in the studied genomes are shown in the same color

Additional file 5: Table S3. Known or putative drug efflux pumps with non-synonymous SNPs in MDR, pre-XDR and XDR M. tuberculosis isolates but not in H37Rv strain.

Additional file 6: Table S4. DNA diversity and selection intensity analysis for the whole genome sequences of M. tuberculosis isolates.

Additional file 7: Script 1. The custom Perl script used to separate each of the indexed samples from raw reads.

Additional file 8: Script 2. The custom Perl script used to retrieve Indel loci from output file (.xmfa) produced by Mauve.

\section{Competing interests}

The authors declare that they have no competing interests.

\section{Authors' contributions}

$\mathrm{CHL}$ and $\mathrm{BZ}$ conceived and designed the study; $\mathrm{CHL}, \mathrm{QW}$ and $\mathrm{HML}$ collected and characterized the isolates that are used in this study; $\mathrm{CHL}$ and $\mathrm{QW}$ performed laboratory experiments; $\mathrm{CHL}, \mathrm{FL}$ and $\mathrm{YH}$ performed the data analysis; QW, HML, GFG and BZ assisted in the data analysis; $\mathrm{CHL}$ wrote the manuscript with assistance from other authors; $\mathrm{FL}, \mathrm{YH}$ and $\mathrm{QW}$ equally contributed to the work. All authors read and approved the final manuscript.

\section{Acknowledgements}

This work was supported by the National Basic Research Program of China (2014CB744400 and 2012CB518700), National Natural Science Foundation of China (81371769), the Ministry of Health and the Ministry of Science and Technology, China (2013ZX10003006 and 2012ZX10005007-011), and the Chinese Academy of Sciences (KJZD-EW-L02), and the Beijing Municipal Science \& Technology Development Program.

\section{Author details}

${ }^{1}$ CAS key Laboratory of Pathogenic Microbiology and Immunology, Institute of Microbiology, Chinese Academy of Sciences, Beijing, China. ${ }^{2}$ Institute for Tuberculosis Research, the 309th Hospital, Beijing, China.

Received: 27 August 2013 Accepted: 10 June 2014 Published: 13 June 2014

\section{References}

1. World Health Organization (WHO): Global tuberculosis report 2013. Geneva: WHO; 2013. Available from: http://apps.who.int/iris/bitstream/10665/91355/ 1/9789241564656 eng.pdf.

2. Zhao Y, Xu S, Wang L, Chin DP, Wang S, Jiang G, Xia H, Zhou Y, Li Q, Ou X, Pang $Y$, Song $Y$, Zhao B, Zhang $H$, He G, Guo J, Wang Y: National survey of drug-resistant tuberculosis in China. N Engl J Med 2012, 366(23):2161-2170.

3. Liu CH, Li L, Chen Z, Wang Q, Hu YL, Zhu B, Woo PC: Characteristics and treatment outcomes of patients with MDR and XDR tuberculosis in a 
TB referral hospital in Beijing: a 13-year experience. PLoS One 2011, 6(4):e19399.

4. Otal I, Martin C, Vincent-Levy-Frebault V, Thierry D, Gicquel B: Restriction fragment length polymorphism analysis using IS6110 as an epidemiological marker in tuberculosis. J Clin Microbiol 1991, 29(6):1252-1254.

5. Kamerbeek J, Schouls L, Kolk A, van Agterveld M, van Soolingen D, Kuijper S, Bunschoten A, Molhuizen H, Shaw R, Goyal M, van Embden J: Simultaneous detection and strain differentiation of Mycobacterium tuberculosis for diagnosis and epidemiology. J Clin Microbiol 1997, 35(4):907-914

6. Supply P, Allix C, Lesjean S, Cardoso-Oelemann M, Rüsch-Gerdes S, Willery E, Savine E, de Haas P, van Deutekom H, Roring S, Bifani P, Kurepina N, Kreiswirth B, Sola C, Rastogi N, Vatin V, Gutierrez MC, Fauville M, Niemann S, Skuce R, Kremer K, Locht C, van Soolingen D: Proposal for standardization of optimized mycobacterial interspersed repetitive unit-variable-number tandem repeat typing of Mycobacterium tuberculosis. J Clin Microbiol 2006, 44(12):4498-4510.

7. Namouchi A, Didelot X, Schock U, Gicquel B, Rocha EP: After the bottleneck: Genome-wide diversification of the Mycobacterium tuberculosis complex by mutation, recombination, and natural selection. Genome Res 2012, 22(4):721-734.

8. Tatusov RL, Koonin EV, Lipman DJ: A genomic perspective on protein families. Science 1997, 278(5338):631-637.

9. Tatusov RL, Fedorova ND, Jackson JD, Jacobs AR, Kiryutin B, Koonin EV Krylov DM, Mazumder R, Mekhedov SL, Nikolskaya AN, Rao BS, Smirnov S, Sverdlov AV, Vasudevan S, Wolf YI, Yin JJ, Natale DA: The COG database: an updated version includes eukaryotes. BMC Bioinformatics 2003, 4:41

10. Sampson SL: Mycobacterial PE/PPE proteins at the host-pathogen interface. Clin Dev Immunol 2011, 2011:497203.

11. van Kessel JC, Hatfull GF: Recombineering in Mycobacterium tuberculosis. Nat Methods 2007, 4(2):147-152.

12. Deitsch KW, Moxon ER, Wellems TE: Shared themes of antigenic variation and virulence in bacterial, protozoal, and fungal infections. Microbiol Mol Biol Rev 1997, 61(3):281-293.

13. Di Pietrantonio T, Correa JA, Orlova M, Behr MA, Schurr E: Joint effects of host genetic background and mycobacterial pathogen on susceptibility to infection. Infect Immun 2011, 79(6):2372-2378.

14. Kennemann L, Didelot X, Aebischer T, Kuhn S, Drescher B, Droege M, Reinhardt R, Correa P, Meyer TF, Josenhans C, Falush D, Suerbaum S: Helicobacter pylori genome evolution during human infection. Proc Natl Acad Sci U S A 2011, 108(12):5033-5038.

15. Wu W, Zheng H, Zhang L, Wen Z, Zhang S, Pei H, Yu G, Zhu Y, Cui Z, Hu Z, Wang H, Li Y: A genome-wide analysis of multidrug-resistant and extensively drug-resistant strains of Mycobacterium tuberculosis Beijing genotype. Mol Genet Genomics 2013, 288(9):425-436.

16. Rosas-Magallanes V, Deschavanne P, Quintana-Murci L, Brosch R, Gicquel $B$ Neyrolles O: Horizontal transfer of a virulence operon to the ancestor of Mycobacterium tuberculosis. Mol Biol Evol 2006, 23(6):1129-1135.

17. Veyrier F, Pletzer D, Turenne C, Behr MA: Phylogenetic detection of horizontal gene transfer during the step-wise genesis of Mycobacterium tuberculosis. BMC Evol Biol 2009, 9:196.

18. Bitter W, Houben EN, Bottai D, Brodin P, Brown EJ, Cox JS, Derbyshire K, Fortune SM, Gao LY, Liu J, Gey van Pittius NC, Pym AS, Rubin EJ, Sherman DR, Cole ST, Brosch R: Systematic genetic nomenclature for type VII secretion systems. PLoS Pathog 2009, 5(10):e1000507.

19. Liu CH, Li HM, Lu N, Wang Q, Hu YL, Yang X, Hu YF, Woo PC, Gao GF, Zhu $B$ : Genomic sequence based scanning for drug resistance-associated mutations and evolutionary analysis of multidrug-resistant and extensively drug-resistant Mycobacterium tuberculosis. J Infect 2012, 65(5):412-422.

20. Pepperell CS, Casto AM, Kitchen A, Granka JM, Cornejo OE, Holmes EC, Birren B, Galagan J, Feldman MW: The role of selection in shaping diversity of natural M. tuberculosis Populations. Plos Pathog 2013, 9(8):e1003543.

21. Etienne G, Malaga W, Laval F, Lemassu A, Guilhot C, Daffe M: Identification of the Polyketide Synthase Involved in the Biosynthesis of the Surface-Exposed Lipooligosaccharides in Mycobacteria. J Bacteriol 2009, 191(8):2613-2621.

22. Rousseau C, Sirakova TD, Dubey VS, Bordat Y, Kolattukudy PE, Gicquel B, Jackson M: Virulence attenuation of two Mas-like polyketide synthase mutants of Mycobacterium tuberculosis. Microbiol-Sgm 2003, 149:1837-1847.
23. Wells RM, Jones CM, Xi ZY, Speer A, Danilchanka O, Doornbos KS, Sun PB, Wu FM, Tian CL, Niederweis M: Discovery of a Siderophore export system essential for virulence of Mycobacterium tuberculosis. Plos Pathog 2013, 9(1):e1003120

24. Portevin D, Gagneux S, Comas I, Young D: Human Macrophage responses to clinical isolates from the Mycobacterium tuberculosis complex discriminate between ancient and modern lineages. Plos Pathog 2011, 7(3):e1001307.

25. Palmer KL, Gilmore MS: Multidrug-resistant enterococci lack CRISPR-cas. MBio 2010, 1(4):e00227. 10.

26. Danilchanka O, Mailaender C, Niederweis M: Identification of a novel multidrug efflux pump of Mycobacterium tuberculosis. Antimicrob Agents Chemother 2008, 52(7):2503-2511.

27. Pasca MR, Guglierame P, Arcesi F, Bellinzoni M, De Rossi E, Riccardi G: Rv2686cRv2687c-Rv2688c, an ABC fluoroquinolone efflux pump in Mycobacterium tuberculosis. Antimicrob Agents Chemother 2004, 48(8):3175-3178.

28. Calgin MK, Sahin F, Turegun B, Gerceker D, Atasever M, Koksal D, Karasartova D, Kiyan M: Expression analysis of efflux pump genes among drug-susceptible and multidrug-resistant Mycobacterium tuberculosis clinical isolates and reference strains. Diagn Microbiol Infect Dis 2013, 76(3):291-297.

29. Jnawali HN, Hwang SC, Park YK, Kim H, Lee YS, Chung GT, Choe KH, Ryoo S: Characterization of mutations in multi- and extensive drug resistance among strains of Mycobacterium tuberculosis clinical isolates in Republic of Korea. Diagn Microbiol Infect Dis 2013, 76(2):187-196.

30. Poudel A, Maharjan B, Nakajima C, Fukushima Y, Pandey BD, Beneke A, Suzuki Y: Characterization of extensively drug-resistant Mycobacterium tuberculosis in Nepal. Tuberculosis (Edinb) 2013, 93(1):84-88.

31. Imperiale BR, Zumarraga MJ, Di Giulio AB, Cataldi AA, Morcillo NS: Molecular and phenotypic characterisation of Mycobacterium tuberculosis resistant to anti-tuberculosis drugs. Int J Tuberc Lung Dis 2013, 17(8):1088-1093.

32. Zhang H, Li D, Zhao L, Fleming J, Lin N, Wang T, Liu Z, Li C, Galwey N, Deng J, Zhou Y, Zhu Y, Gao Y, Wang T, Wang S, Huang Y, Wang M, Zhong Q, Zhou L, Chen T, Zhou J, Yang R, Zhu G, Hang H, Zhang J, Li F, Wan K, Wang J, Zhang XE, Bi L: Genome sequencing of 161 Mycobacterium tuberculosis isolates from China identifies genes and intergenic regions associated with drug resistance. Nat Genet 2013, 45(10):1255-1260.

33. Warner DF, Mizrahi $\mathrm{V}$ : Complex genetics of drug resistance in Mycobacterium tuberculosis. Nat Genet 2013, 45(10):1107-1108.

34. Gandhi NR, Brust JC, Moodley P, Weissman D, Heo M, Ning Y, Moll AP, Friedland GH, Sturm AW, Shah NS: Minimal diversity of drug-resistant Mycobacterium tuberculosis strains, South Africa(1.). Emerg Infect Dis 2014, 20(3):394-401.

35. Benson G: Tandem repeats finder: a program to analyze DNA sequences. Nucleic Acids Res 1999, 27(2):573-580.

36. Coll F, Mallard K, Preston MD, Bentley S, Parkhill J, McNerney R, Martin N, Clark TG: SpolPred: rapid and accurate prediction of Mycobacterium tuberculosis spoligotypes from short genomic sequences. Bioinformatics 2012, 28(22):2991-2993.

37. Delcher AL, Bratke KA, Powers EC, Salzberg SL: Identifying bacterial genes and endosymbiont DNA with Glimmer. Bioinformatics 2007, 23(6):673-679.

38. Lowe TM, Eddy SR: tRNAscan-SE: a program for improved detection of transfer RNA genes in genomic sequence. Nucleic Acids Res 1997, 25(5):955-964.

39. Lagesen $\mathrm{K}$, Hallin P, Rodland EA, Staerfeldt HH, Rognes T, Ussery DW: RNAmmer: consistent and rapid annotation of ribosomal RNA genes. Nucleic Acids Res 2007, 35(9):3100-3108.

40. Aziz RK, Bartels D, Best AA, DeJongh M, Disz T, Edwards RA, Formsma K, Gerdes S, Glass EM, Kubal M, Meyer F, Olsen GJ, Olson R, Osterman AL, Overbeek RA, McNeil LK, Paarmann D, Paczian T, Parrello B, Pusch GD, Reich C, Stevens R, Vassieva O, Vonstein V, Wilke A, Zagnitko O: The RAST Server: rapid annotations using subsystems technology. BMC Genomics 2008, 9:75.

41. Li R, Li Y, Fang $X$, Yang H, Wang J, Kristiansen K, Wang J: SNP detection for massively parallel whole-genome resequencing. Genome Res 2009, 19(6):1124-1132.

42. Li H, Durbin R: Fast and accurate long-read alignment with BurrowsWheeler transform. Bioinformatics 2010, 26(5):589-595.

43. Li H, Handsaker B, Wysoker A, Fennell T, Ruan J, Homer N, Marth G, Abecasis G, Durbin R, Genome Project Data Processing S: The Sequence Alignment/ Map format and SAMtools. Bioinformatics 2009, 25(16):2078-2079.

44. Darling AC, Mau B, Blattner FR, Perna NT: Mauve: multiple alignment of conserved genomic sequence with rearrangements. Genome Res 2004, 14(7):1394-1403. 
45. Kurtz S, Phillippy A, Delcher AL, Smoot M, Shumway M, Antonescu C, Salzberg SL: Versatile and open software for comparing large genomes. Genome Biol 2004, 5(2):R12.

46. Krzywinski M, Schein J, Birol I, Connors J, Gascoyne R, Horsman D, Jones SJ, Marra MA: Circos: an information aesthetic for comparative genomics. Genome Res 2009, 19(9):1639-1645.

47. Qi J, Zhao F: inGAP-sv: a novel scheme to identify and visualize structural variation from paired end mapping data. Nucleic Acids Res 2011, 39(Web Server issue):W567-W575.

48. Grissa I, Vergnaud G, Pourcel C: CRISPRFinder: a web tool to identify clustered regularly interspaced short palindromic repeats. Nucleic Acids Res 2007, 35(Web Server issue):W52-W57.

49. Sandgren A, Strong M, Muthukrishnan P, Weiner BK, Church GM, Murray MB Tuberculosis drug resistance mutation database. PLoS Med 2009, 6(2):e2.

50. Librado P, Rozas J: DnaSP v5: a software for comprehensive analysis of DNA polymorphism data. Bioinformatics 2009, 25(11):1451-1452.

51. Tamura K, Peterson D, Peterson N, Stecher G, Nei M, Kumar S: MEGA5: Molecular Evolutionary Genetics Analysis using maximum likelihood, evolutionary distance, and maximum parsimony methods. Mol Biol Evol 2011, 28(10):2731-2739.

doi:10.1186/1471-2164-15-469

Cite this article as: Liu et al:: Comparative genomic analysis of

Mycobacterium tuberculosis clinical isolates. BMC Genomics 2014 15:469.

\section{Submit your next manuscript to BioMed Central and take full advantage of:}

- Convenient online submission

- Thorough peer review

- No space constraints or color figure charges

- Immediate publication on acceptance

- Inclusion in PubMed, CAS, Scopus and Google Scholar

- Research which is freely available for redistribution 